\title{
Forecast of the morphological composition of municipal solid waste in Moscow (Russia)
}

\author{
Grigorii Kozlov ${ }^{1}$, and Mikhail Pushkarev ${ }^{1, *}$ \\ ${ }^{1}$ Saint-Petersburg State Institute of Technology, 190013, 26 Moskovsky prospect, St. Petersburg, \\ Russia
}

\begin{abstract}
The article provides data on forecasting the composition of municipal solid waste (MSW) in the city of Moscow (Russia). The paper proposes a methodology for predicting the morphological composition of MSW and checks its operability. It was found that using the regression equations it is possible to fairly reliably (with an error within 5\%) predict the composition of the main fractions of MSW (food waste, polymers, paper, screenings, etc.), however, it is almost impossible to predict the particle size distribution in this way, since it depends on changes consumer preferences and should be evaluated in an expert way.
\end{abstract}

\section{Introduction}

Municipal solid waste (MSW) processing enterprises have been operating for a long period, however, their design is based on data on the composition of MSW of previous years and the current period, and the composition of the waste varies significantly over time. Thus, monitoring and forecasting the composition of MSW is absolutely necessary for organizing MSW handling, developing technologies for their disposal and designing industry facilities. The experience of designing waste sorting stations for various regions of Russia has shown that forecasting the composition of the waste must be carried out for each specific facility in the industry (collection area), and not for the region in general, which poses the problem of applying forecasting methods available to specialists in economic and engineering specialties, and on the other hand open for adjustment as new data is received.

\section{Results and discussion}

When analyzing the literature data [1,2], it was found that the morphological composition of MSW within the historical time period during which there are no revolutionary changes in science and technology (invention of polymers) and in infrastructure (transition to central heating, sewage), as well as decisive measures are not taken to create MSW processing systems, it is determined mainly by economic factors. We have shown that the following economic indicators correlate most closely with the waste composition: the number of personal cars per 1000 people, gross domestic product (GDP) and gross regional product (GRP). Since the forecast should take into account the specifics of the region, in order to

\footnotetext{
${ }^{*}$ Corresponding author: malexpush@bk.ru
} 
build the forecast model, it was not taken Russia's GDP as a whole, but the GRP of the corresponding region (Moscow) in millions of rubles, which also closely correlates with the composition of the waste. Economic indicators are taken on the Official website of the Federal State Statistics Service of Russia (Socio-economic indicators. Official site of the Federal State Statistics Service. https://www.gks.ru/folder/210/document/) - table 1.

Table 1. Gross regional product of Moscow (Russia) by years

\begin{tabular}{|c|c|}
\hline Year & GRP Moscow in millions of rubles \\
\hline 2002 & 1999995,3 \\
\hline 2003 & 2441425,8 \\
\hline 2004 & 2759100,9 \\
\hline 2005 & 4005883 \\
\hline 2006 & 5145873,9 \\
\hline 2007 & 6731188,9 \\
\hline 2008 & 8441206,2 \\
\hline 2015 & 13532598 \\
\hline
\end{tabular}

In the work we used the data previously obtained by us [3, 4]. Over the first decade of the 21 st century, the content of polymers, paper, textiles, glass, wood, leather and rubber increased in the MSW of Moscow. The share of food waste, ferrous and non-ferrous scrap metal, the "other" fraction and screenings decreased. The share of PET, polymers, screenings, and textiles has changed most significantly in 2002-2008 in relative terms. The most stable fractions are "stones", "wood", "glass", "non-ferrous metals". Based on the received average annual data, regression equations were constructed that allow calculating the planned composition of the waste, based on the forecast of the gross regional product of Moscow.

The values of the fraction content obtained on the basis of regression equations were compared with official data on the composition of MSW in Moscow for 2015 (source: The territorial scheme of waste management, including municipal solid waste, was approved by the Government of Moscow of August 9, 2016 N 492-PP "On approval of the territorial scheme of waste management, including solid municipal waste" GARANT.RU, https://http://www.garant.ru/products/ipo/prime/doc/71363504/\#ixzz65LN4Pxhu) (Figures $1-7)$.

The total content of the "paper" fraction is well predicted - the actual value differs from the calculated one by $4 \%$, however, the particle size distribution of the "Paper" fraction is forecasted much worse - the content of elements of the fraction of 15-60 mm and $>250 \mathrm{~mm}$ has fallen so sharply, but the content of elements of the fraction of size has grown 60-150 $\mathrm{mm}$. This trend can be explained by changes in the gadget market. Changes in the particle size distribution of the "food waste" fraction are expressed in a decrease in the proportion of small scraps of 15-60 mm and an increase in the proportion of large scraps of 60-150 $\mathrm{mm}$. The discrepancy between the actual total share of food waste and the forecast is $2.8 \%$. A similar trend is observed for polymers - the discrepancy between the actual total content and the predicted is $4.3 \%$, and the particle size distribution varies greatly. PET is an integral part of the "polymers" fraction and its variation is also very strong, and the forecast does not coincide with the actual content. The forecasting of the glass content should also be recognized as unsatisfactory - the particle size distribution does not coincide with the predicted, and the total content differs from the predicted one by two times. The content of ferrous and non-ferrous metal does not exceed $1.2 \%$ and $0.8 \%$, respectively. Their change is almost imperceptible, due to the fact that the collection of metals has poured into an independent industry and the metals in MSW are presented in standard food packaging and small household items. The content of the "wood" fraction diverges from the forecast by 
almost 1.5 times, but the actual content is not exceeds $1.7 \%$ with a forecast of $2.6 \%$. The forecast equation for the dependence of the total textile content on the GRP of Moscow ( $\mathrm{y}=$ $\left.3 \mathrm{E}-07 \mathrm{x}+3.29 ; \mathrm{R}^{2}=0.9755\right)$ gives a value of $7.36 \%$ with the actual $3.6 \%$. The same situation with the "leather and rubber" fraction with the calculated value of the total content of this fraction $\left(\mathrm{y}=4 \mathrm{E}-08 \mathrm{x}+5.116 ; \mathrm{R}^{2}=0.9412\right)$ equal to $5.66 \%$, only $0.7 \%$ is observed. The total content of the "other" fraction differs from the actual one by $17 \%$, particle size distribution is poorly predicted, with the exception of the 15-60 mm fraction. The forecast for the content of the "screening" fraction coincides with the actual content - the discrepancy is $4.3 \%$.
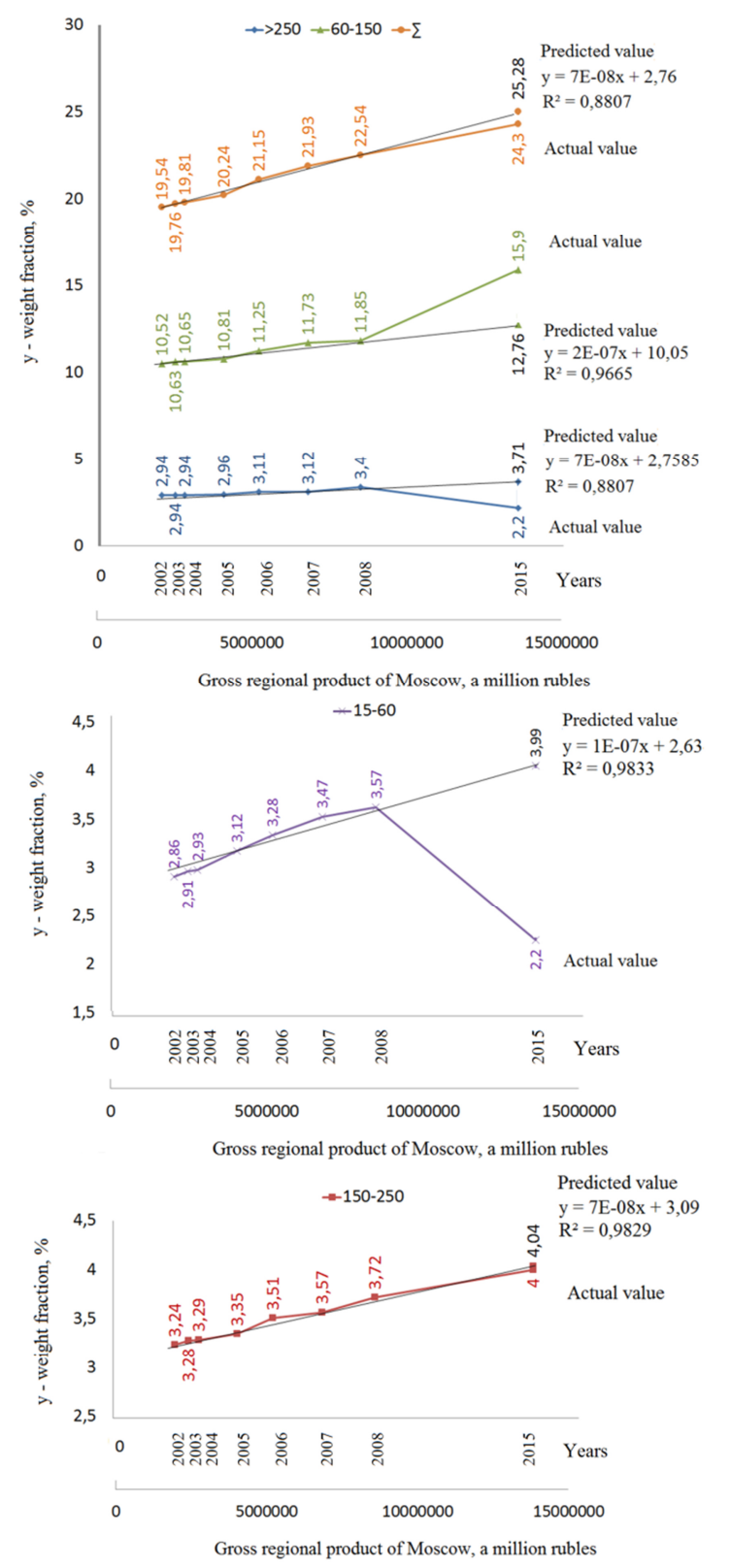

Fig. 1. Dependence of the content of particle size distribution components of the MSW fraction "paper" on the GRP of Moscow ( 1 dollar $=64$ rubles; 1 euro $=70$ rubles $)$ 

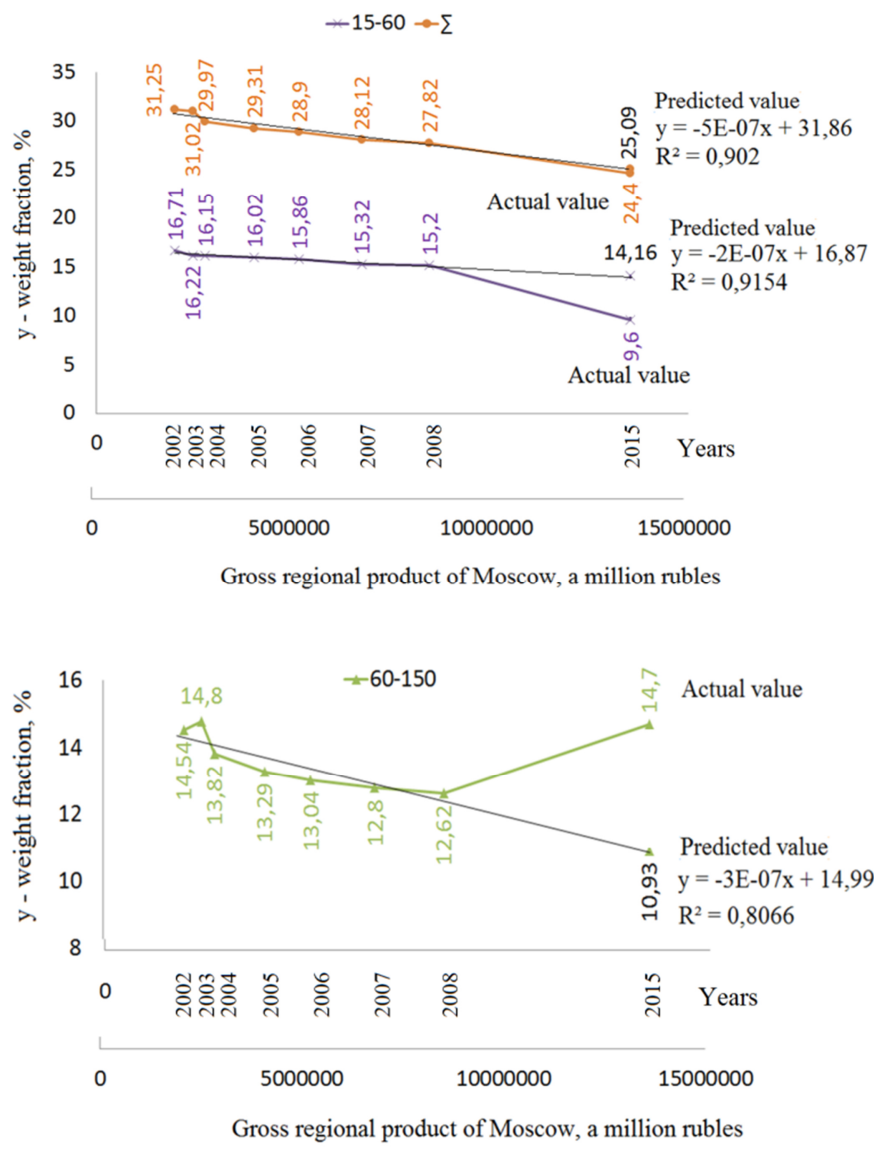

Fig. 2. Dependence of the content of particle size distribution components of the MSW fraction "food waste" on the GRP of Moscow ( 1 dollar $=64$ rubles; 1 euro $=70$ rubles $)$ 


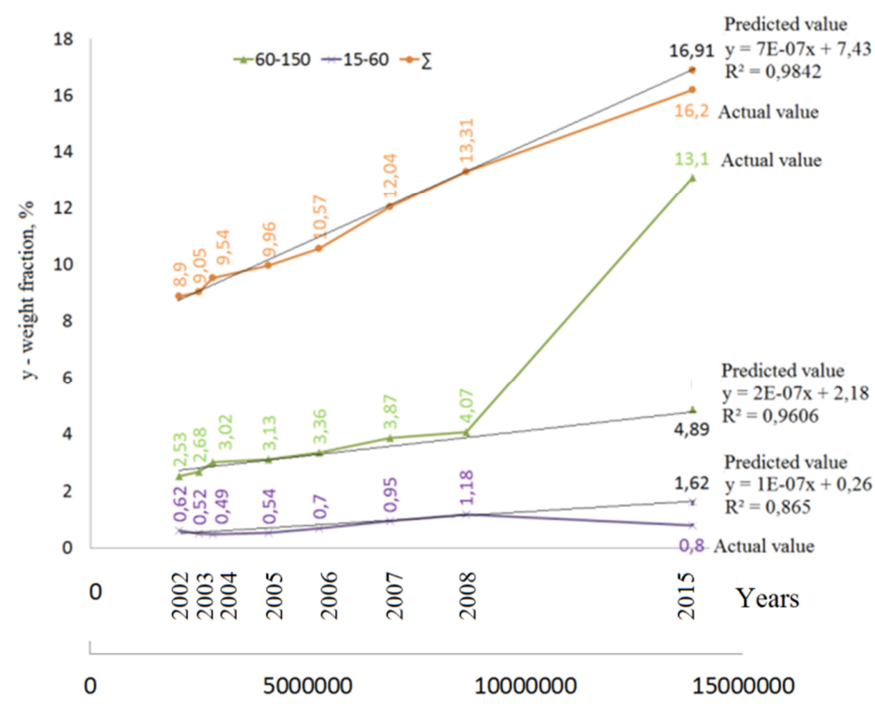

Gross regional product of Moscow, a million rubles

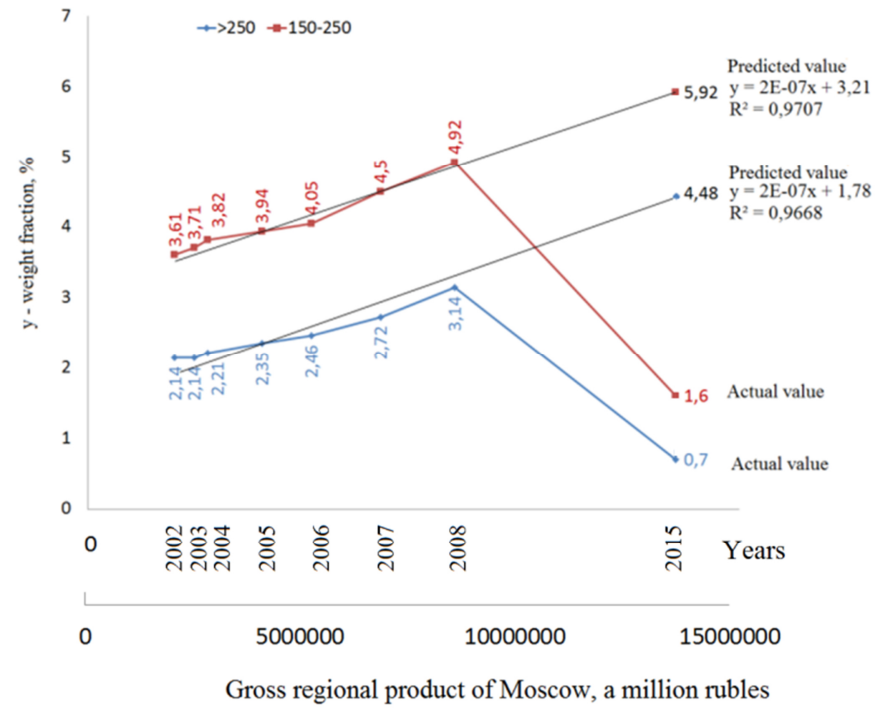

Fig. 3. Dependence of the content of particle size components of the fraction of MSW "polymers" on the GRP of Moscow ( 1 dollar $=64$ rubles; 1 euro $=70$ rubles $)$ 

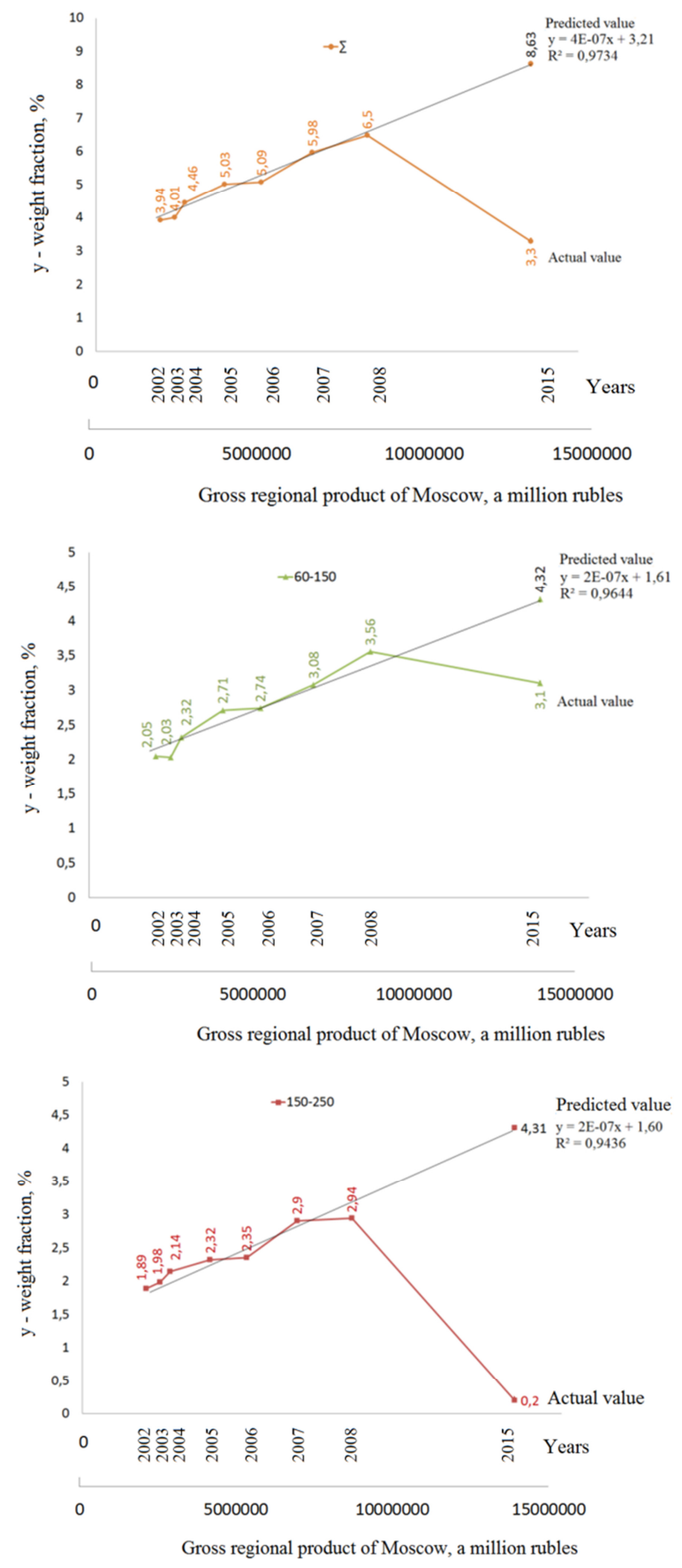

Fig. 4. Dependence of the content of particle-size components of the fraction of solid waste "including PET" on the GRP of Moscow ( 1 dollar $=64$ rubles; 1 euro $=70$ rubles) 

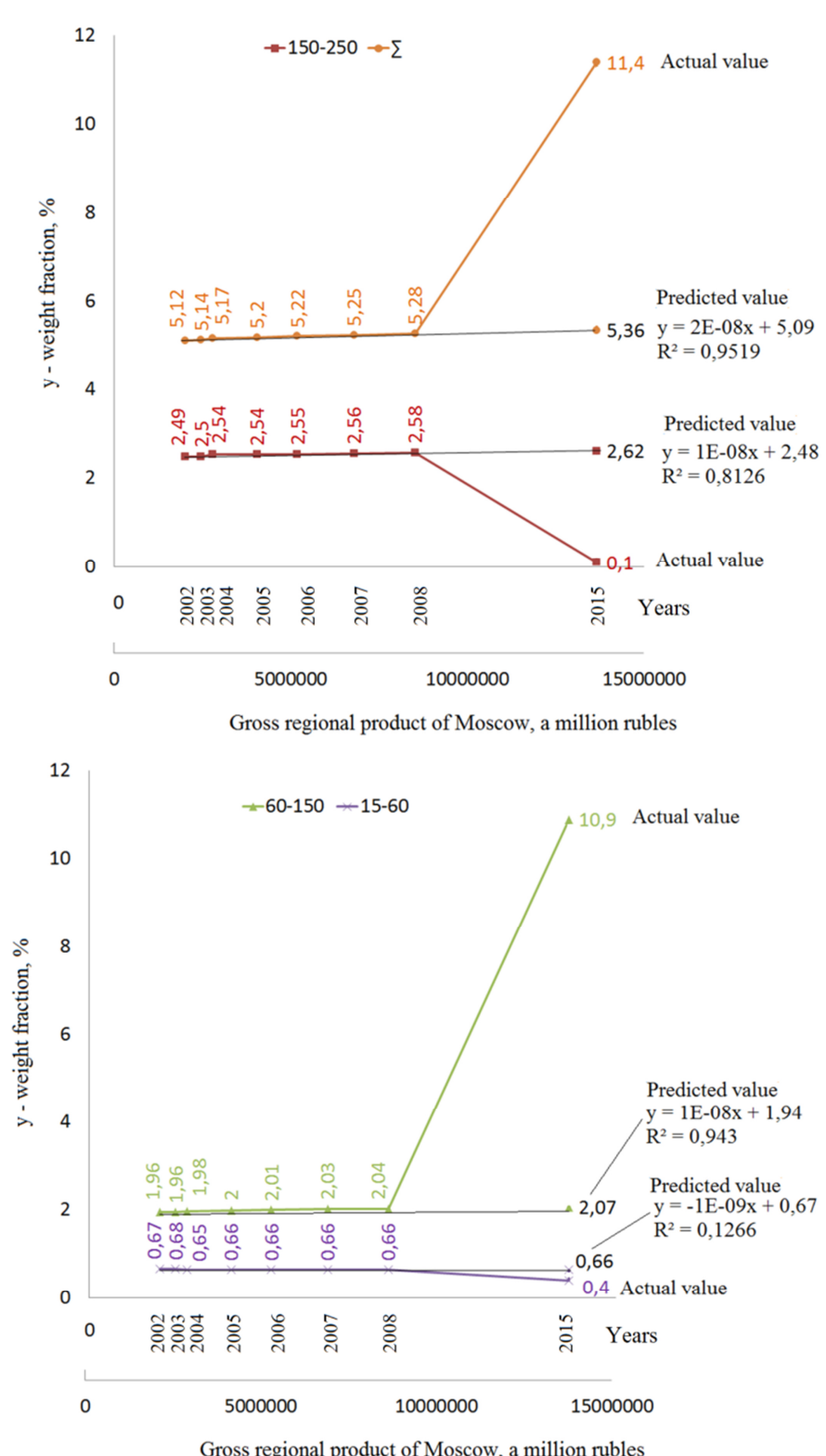

Fig. 5.- Dependence of the content of particle-size components of the fraction of MSW "glass" on the GRP of Moscow ( 1 dollar $=64$ rubles; 1 euro $=70$ rubles $)$ 

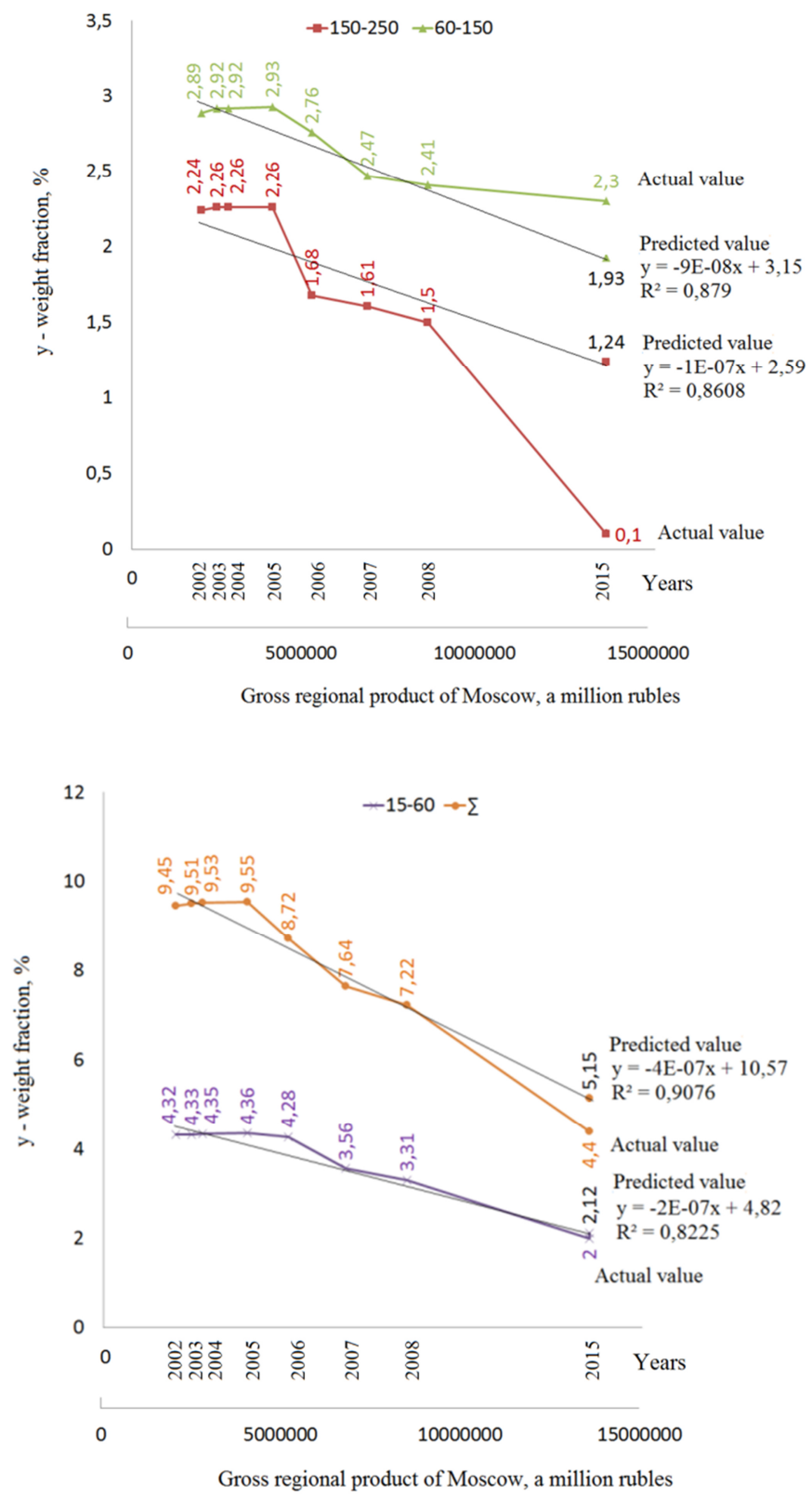

Fig. 6. Dependence of the content of particle size distribution components of the MSW fraction "other" on the GRP of Moscow ( 1 dollar $=64$ rubles; 1 euro $=70$ rubles $)$ 


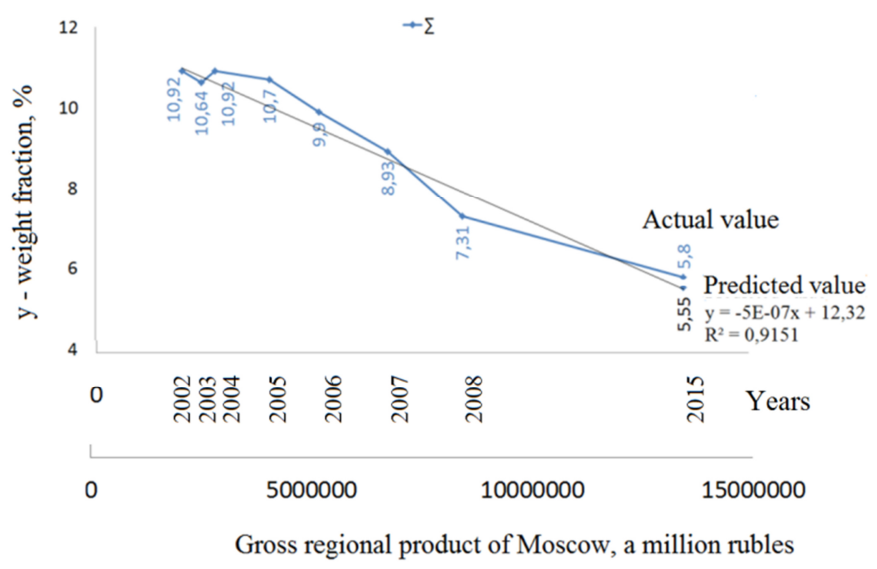

Fig. 7. Dependence of the content of particle-size components of the fraction of solid waste "screening" on the GRP of Moscow ( 1 dollar $=64$ rubles; 1 euro $=70$ rubles)

Thus, the total content of the main fractions is reliably forecasted: "paper", "food waste", "polymers", "screening", the "other" fraction is somewhat less reliable.

\section{Conclusions}

1. Statistical methods are suitable only for predicting the total amount of fractions in the composition of municipal solid waste, changes in the particle size distribution of fractions must be predicted by an expert method based on trends in the consumption of a wide range of goods and the development of materials science

2. Our forecast model allows us to accurately predict the composition of the waste for a period of 7-10 years, which allows us to reliably design technological equipment for this period. The forecast model is also open to adjustment as new data is received.

\section{References}

1. I. V. Zamotaev, I. V. Ivanov, P. V. Mikheev, V. P. Belobrov, Eurasian soil science, 51(7), 827-842 (2018).

2. O.V. Ischenko, D.S. Yakshilov, A.V. Garabajiu, G.V. Kozlov, Moscow International Scientific and Practical Conference "Biotechnology: Ecology of Large Cities", 176 (2010). 3. N.V. Martynov, D.S. Yakshilov, D.V. Suvorov, A.Kh. Nikogosov, G.V. Kozlov, Int. conf. "Chemistry and complete processing of forest biomass", 79 (St. Petersburg, 2010). 4. D.V. Suvorov, A.K. Nikogosov, D.S. Yakshilov, G.V. Kozlov, A.V. Garabagiu, N.V. Martynov, Ecology of urbanized territories 2, 69-72 (2010). 